\title{
DE PHILOSOPHORUM GRAECORUM SILENTIO MYSTICO
}

SCRIPSIT

ODO CASEL

모에

VERLAG VON ALFRED TÖPELMANN IN GIESSEN 1919 


\section{RELIGIONSGESCHICHTLICHE VERSUCHE UND VORARBEITEN}

BEGRUNDET VON ALBRECHT DIETERICH UND RICHARD WÜNSCH IN VERBINDUNG MIT LUDWIG DEUBNER HERAUSGEGEBEN VON LUDOLF MALTEN UND OTTO WEINREICH IN KONIGSBERG / PR.

IN HEIDELBERG

XVI. BAND 2. HEFT 


\title{
ILDEFONSO HERWEGEN
}

\author{
ABBATI
}

PIETATIS ERGO 

Universitatis Fridericiae Guilelmiae Bonnensis amplissimus philosophorum ordo hac commentatione iudicio eius subiecta autumno a. 1918 praemio et paullo post summis in philosophia honoribus dignum me habuit. Cui maximas ago gratias et imprimis Augusto Brinkmann, cuius doctrina et benignitas quantum huic libro utilitatis attulerit unaquaeque fere pagina testatur.

Hac de Graecorum silentio mystico commentatione viam mihi parasse videor, qua mox de Christianorum silentii mystici causis et primordiis scribere aggrediar.

o. C. 
